\title{
Improved and Novel Methods Of Pharmaceutical Calculations
}

\author{
R. Subramanya \\ Cheluvamba Hospital, Karnataka, Mysore-570 001, India.
}

\begin{abstract}
It is a review and research article wherein general equations are derived for some problems and new rules are framed on percentage calculations, ratio and proportions and on variation of surface area with respect to size of the particle. Percentage calculations are projected from novel angles. Dimensions or units of quantities are retained up to the result. An easy method for solution of ratio and proportions are suggested. Problems solved by alligation method in the books are solved by simple algebraic method with little new rules.
\end{abstract}

Keywords: axis, decimal, percentage, serially, syntax,

\section{Introduction}

This article is review of books [1] \& [2]. section-2, contains the review on basics of percentage calculations. A new general equation is furnished at the end of this section to ease out solving of such problems. In most of the books same mistake is committed as in [3] of [1]. Hence, proof of these general equations are given to confirm the mathematical statements.

In section 3, problems solved by dimensional analysis are solved by other methods that are easier than dimensional analysis.[4]. In the second ratio of set of equivalent ratios of first method, different dimensions are changed into same kind of dimensions i.e., ml, which has made the solution of problem easier and shorter. Similarly second method is also easier and shorter.

A general equation for the total surface area with respect to the decrease in the particle size is derived. Accordingly, total surface area is inversely proportional to the size of the particle. Because the equation belongs to magic series, increase in surface area w.r.t the decrease in size of the particle is a wonder which is shown in example problems.

Section 5 gives a synoptic view of basic measurements.

Section 6 contains new ideas and laws on percentage calculations. Some of the problems are solved by using simple mathematical operators like addition, subtraction, appropriate factor, and by simple division. In most of the books proportional method is used for solving these problems. In this paper while solving alligation problems new methods are used. And, algebraic solutions with multiple results are shown.

Section-7, gives a simple equation for conversion of percentage to milligram per $\mathrm{ml}$ and vice versa.

In section-8, new method is furnished to solve the problems on dilution

In section-9, some problems are solved in different and easy methods than in books.

\section{Review on Fundamentals of Percentage Calculations:}

2.1. Convert $\frac{3}{8}$ to percent $[3]$

Given calculation in the book is $\frac{3}{8} \times 100=37.5 \%$

The above equation does not satisfy the meaning of the symbol '=' (equals) used in between the expressions $\left(\frac{3}{8} \times 100\right)$ and $37.5 \%$.

: Actual value of $\frac{3}{8} \times 100=37.5$

And37.5 = $37.5 \times\left(\frac{100}{100}\right)$

$: \quad=3750 \%$ 
The correct method of solution is as following

$: \frac{3}{8}=0.375$

$:=0.375 \times \frac{100}{100}$

$:=\frac{37.5}{100}$

: $=37.5 \%$

2.2. . A 1: 1000 solution has been ordered..You have a $1 \%$ solution, a $0.5 \%$ solution, a $0.1 \%$ solution in

stock. Will one of these work to fill the order. [4]

Solution: $1: 1000=\frac{1}{1000}=\frac{1}{10 \times 100}=0.1 \%$

In comparison with solution of [4]in [1],a few steps are reduced.

2.3. Express $0.02 \%$ as ratio strength.

Solution: $0.02 \%=\frac{0.02}{100}=\frac{\frac{2}{100}}{100}=\frac{2}{10000}=\frac{1}{5000}=1: 5000$

2.4. . Give the decimal fraction and percent equivalent of $\frac{1}{45}$

$: \frac{1}{45}=\frac{1}{45} \times \frac{100}{100}$

$:=\frac{2.22}{100}$

$: \quad=2.22 \%$

\subsection{General Equation:}

$: x \%=\frac{x}{100}----------(1)$

Whence $x$ is a real number

: Hence, $x=100 x \%$

2.6. Proof of (1) and (2):

Let $a$ be a real number,

: Then, $a=a \times 1$

: Also, $a=a \times \frac{100}{100}$

$: \quad=\frac{100 a}{100}$

: $\quad a=100 a \%$

: And, $a \%=\frac{a}{100}$

:Further, by cross multiplication we have $100 a \%=a$

: $100 \times \frac{a}{100}=a$

:Consequently, $a=a$

\section{Another way for dimensional analysis:}

3.1. How many fluidounces (fi.oz) are there in 2.5 liters $(L)$ ? [5]

...Method-1:

: Given, 1 fluidounce $=29.57 \mathrm{ml}$

: $\frac{2.5 \mathrm{~L}}{1 \mathrm{fl} . \mathrm{oz}}=\frac{2500 \mathrm{ml}}{29.57 \mathrm{ml}}=\frac{2500}{29.57}=84.55$

Method -2: 
1 fl.oz. $=29.57 \mathrm{ml}$

.....Multiplying both sides by the factor $\frac{2500}{29.57}$ that modifies $29.57 \mathrm{ml}$ to required quantity, we get

: 1 fl. oz. $\times \frac{2500}{29.57}=29.57 \mathrm{ml} \times \frac{2500}{29.57}$

$: 84.55 f l . o z .=2.5 L$

\section{General equation to find the total surface area of particles. (Imaginary and ideal case).[6].}

4.1. A general equation is derived to find the total surface area of cubes when a cube is divided serially along the $\mathrm{xy}, \mathrm{yz}$ and $\mathrm{zx}$-planes. When a cube is divided along the planes of axes $\mathrm{x}, \mathrm{y}$ and $\mathrm{z}$, it gets divided into eight equal cubes at every time i.e. after every set of cutting. When a cube is cut through $\mathrm{x}, \mathrm{y}$ and $\mathrm{z}$ plane it is called, 'a set of cutting'.

The sum of the surface area of cubes at ' $\mathrm{n}$ 'th' set of cutting is : $A=2^{n+1} \times 3 l^{2}$ square units--(3)

Where, 'A' denotes the sum of surface area of cubes and ' $n$ ' the ordinal value of set of cuttings from the first cube. Hence $\mathrm{n}$ is a set of whole number, i.e. $n=\{0,1,2,3 \ldots\}$

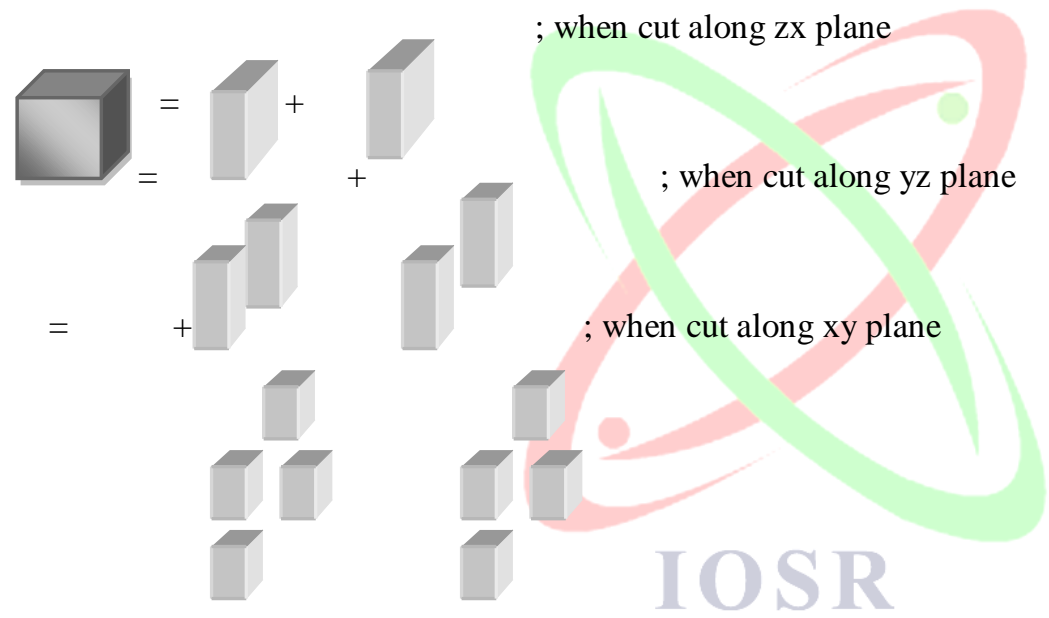

Fig.1. A typical view of a set of cuttings of the cubes across the $\mathrm{zx}, \mathrm{yz}$ and $\mathrm{xy}$ planes.

To the $1^{\text {st }}$ cube, ordinal number of set of cutting is 0 , i.e., $\mathrm{n}=0$, and if he length is $l$ units

Total surface area of first cube is : $A=2^{n+1} \times 3 \times l^{2}$

: $\quad=2^{1} \times 3 \times l^{2}$

$\begin{array}{ll}: & =6 l^{2}\end{array}$

$:$ And if $=1 ; A=2^{n+1} \times 3 l^{2}$

$\quad=2^{2} \times 3 l^{2}$

: $\quad=12 l^{2}$

:And if $n=2 ; A=2^{n+1} \times 3 \times l^{2}$

: $\quad=24 l^{2}$

: And so on. 
4.2. Derivation of equation : $A=2^{n+1} \times 3 l^{2}$

To start with, cube has six faces and if its length is $l$ units the total surface area of the cube, when no cut is done along the axes is

: $\quad a_{0}=$ one cube $\times$ number of faces $\times$ area of one surface

:i.e. $a_{0}=1 \times 6 \times l^{2}$

To make the above equation look like rest of the equations, it can be written as

: $\quad a_{0}=8^{0} \times 6 \times\left(\frac{l}{2^{0}}\right)^{2}$

when this cube is cut across the Co-ordinate planes we get 8 cubes of dimensions equal to $\frac{l}{2}$ units each.

$\therefore \quad \therefore a_{1}=8 \times 6 \times\left(\frac{l}{2}\right)^{2}$

: Further, $a_{2}=8^{2} \times 6 \times\left(\frac{l}{2^{2}}\right)^{2}$

:Finally, equation for $n^{\text {th }}$ term is

: $a_{n}=8^{n} \times 6 \times\left(\frac{l}{2^{n}}\right)^{2}$

:To simplify this equation, it can be written as

:

: Further, $a_{n}=2^{3 n+1} \times 3 l^{2}\left(2^{-2 n}\right)$

:Replacing $a_{n}$ by A, and simplifying further we get

$: A=3\left(2^{n+1} l^{2}\right)$

$:=\left(2^{n+1}\right) 3 l^{2}$

Thus derived.

4.3. For example when $n=0$

Surface area of the cube of length $1 \mathrm{~cm}$ is

$:\left(2^{n+1}\right) 3 l^{2} \mathrm{~cm}^{2}=2 \times 3 \mathrm{~cm}^{2}$

$: \quad=6 \mathrm{~cm}^{2}$

This is equal to the area of $2 \mathrm{~cm} \times 3 \mathrm{~cm}$ rectangle.

Further when $n=5$ ( 5 set of cuts) and $l=1 \mathrm{~cm}$,

:Then, $\left(2^{n+1}\right) 3 l^{2}=2^{6} \times 3$

: $\quad=192 \mathrm{~cm}^{2}$

This area is equal to the area of $12 \mathrm{~cm} \times 16 \mathrm{~cm}$ rectangle.

And when $n=20$ and $l=1 \mathrm{~cm}$

$:\left(2^{n+1}\right) 3 l^{2}=2^{21} \times 3$

$: \quad=6291456 \mathrm{~cm}^{2}$

This is approximately equal to the area of $2.5 \mathrm{~m} \times 2.51 \mathrm{~m}$ dimension. 
IOSR Journal of Pharmacy

Vol. 2, Issue 1, Jan-Feb.2012, pp. 113-129

\section{MEASURMENT}

Table-1:.Measurement Of Length, Mass And Volume (SI Units)

\begin{tabular}{|c|c|c|c|}
\hline Name of the unit & $\begin{array}{l}\text { Expressed in terms } \\
\text { of } \mathrm{m} / \mathrm{L} / \mathrm{g}\end{array}$ & $\begin{array}{l}\text { Values expressed in } \\
\text { scientific notation }\end{array}$ & $\begin{array}{l}\text { Fractional notation in } \\
\mathrm{m} / \mathrm{L} / \mathrm{g}\end{array}$ \\
\hline 1 Kilo-meter/liter/gram. $(\mathrm{km} / \mathrm{kL} / \mathrm{kg})$ & $1000 \mathrm{~m} / \mathrm{L} / \mathrm{g}$ & $10^{3} \mathrm{~m} / \mathrm{L} / \mathrm{g}$ & \\
\hline 1 hecto-meter/liter/gram. (hm/hL/hg) & $100 \mathrm{~m} / \mathrm{L} / \mathrm{g}$ & $10^{2} \mathrm{~m} / \mathrm{L} / \mathrm{g}$ & \\
\hline 1 deka-meter/liter/gram. dam/daL/dag & $10 \mathrm{~m} / \mathrm{L} / \mathrm{g}$ & $10^{1} \mathrm{~m} / \mathrm{L} / \mathrm{g}$ & \\
\hline 1 meter/liter/gram. m/L/g & $1 \mathrm{~m} / \mathrm{L} / \mathrm{g}$ & $10^{0} \mathrm{~m} / \mathrm{L} / \mathrm{g}$ & \\
\hline 1 deci-meter/liter/gram. dm/dL/dg & $0.1 \mathrm{~m} / \mathrm{L} / \mathrm{g}$ & $10^{-1} \mathrm{~m} / \mathrm{L} / \mathrm{g}$ & $\left(\frac{1}{10}\right)^{t h} \mathrm{~m} / L / g$ \\
\hline 1 centi-meter/liter/gram. $\mathrm{cm} / \mathrm{cL} / \mathrm{g}$ & 0.01 & $10^{-2} \mathrm{~m} / \mathrm{L} / \mathrm{g}$ & $\left(\frac{1}{100}\right)^{t h} \mathrm{~m} / L / g$ \\
\hline 1 milli-meter/liter/gram $(\mathrm{mm} / \mathrm{mL} / \mathrm{mg})$ & $0.001 \mathrm{~m} / \mathrm{L} / \mathrm{g}$ & $10^{-3} \mathrm{~m} / \mathrm{L} / \mathrm{g}$ & $\left(\frac{1}{1000}\right)^{t h} m / L / g$ \\
\hline $\begin{array}{l}1 \mathrm{micro}-\mathrm{meter} / \mathrm{liter} / \mathrm{gram} \\
(\mathrm{mcm} / \mathrm{mcL} / \mathrm{mcg})\end{array}$ & $0.000001 \mathrm{~m} / \mathrm{I}$ & $10^{-6} \mathrm{~m} / \mathrm{L} / \mathrm{g}$ & $\begin{array}{l}\left(\frac{1}{1000000}\right)^{t h} \\
\mathrm{~m} / \mathrm{L} / \mathrm{g}\end{array}$ \\
\hline 1 nano-meter/liter/gram. $(\mathrm{nm} / \mathrm{nL} / \mathrm{ng})$ & $\begin{array}{l} \\
0.000000001 \\
\mathrm{~m} / \mathrm{L} / \mathrm{g}\end{array}$ & $10^{-9} \mathrm{~m} / \mathrm{L} / \mathrm{g}$ & $\begin{array}{c}\left(\frac{1}{1000000000}\right)^{t h} \\
\mathrm{~m} / \mathrm{L} / \mathrm{g}\end{array}$ \\
\hline
\end{tabular}

Note: all measurements are basically compared with $\mathrm{m} / \mathrm{L} / \mathrm{g}$ in this table

5.2. Add $0.5 \mathrm{~kg}, 50 \mathrm{mg}, 2.5 \mathrm{dg}$, reduce the result to grams.[7]

$:=0.5 \mathrm{~kg}+50 \mathrm{mg}+2.5 \mathrm{dg}$

$: \quad=0.5 \times(1 \mathrm{~kg})+50 \times(1 \mathrm{mg})+2.5 \times(1 \mathrm{dg})$

Conversion factors are

$: 1 \mathrm{~kg}=1000 \mathrm{~g}, 1 \mathrm{mg}=\frac{1}{1000} \mathrm{~g}, 1 \mathrm{dg}=\frac{1}{10} \mathrm{~g}$

: Substituting the above values in (4), we get 


$$
\begin{aligned}
& :=0.5 \times(1000 g)+50 \times\left(\frac{1}{1000} g\right)+2.5 \times\left(\frac{1}{10} g\right) \\
& :=0.5 \times(1000 g)+50 \times\left(\frac{1}{1000} g\right)+2.5 \times\left(\frac{1}{10} g\right) \\
& :=500 g+0.05 g+0.25 g \\
& :=500.3 g
\end{aligned}
$$

\section{SYNTAX OF PERCENTAGE (\%) AND PARTS PER n (PPn)CALCULATIONS}

Percent means 'for every hundred'. Symbolically it is written as \%. And mathematically it is written as the ratio $x / 100$ or $\frac{x}{100}$. The bar between two numbers represents the phrase 'for every'. It can also be read as 'Parts per cent' the word cent is Latin derivative which means, hundred. And this 'Parts per cent' can be abbreviated as PPc. I suggest to write this as PPh which is the abbreviation of 'Parts Per Hundred'. This kind of abbreviation helps to extend the same idea to any quantity. For example PPt for parts per ten,. i.e., PPh for 'Parts Per Hundred, PPth, parts per thousand, PPtth 'Parts Per Ten Thousand', PPhth 'Parts Per Hundred Thousand', Parts Per Million 'PPm'and so on. Alpha numerically it can also be written as $P P 10^{0}$, PP10, $P P 10^{2}, P P 10^{3} \cdots P P 10^{n}$. Usually, comparison is done in multiple of 10.

Although general expression Parts Per $\mathrm{n}$ can be written as $P P n$, where $n$ is a positive intiger.

If $x$ is the number of parts then general expression is : $x P P n$.

Mathematically xPPn can be written as following in the fractional form

The staked fractional notation of $\mathrm{xPPn}$ is $\frac{x}{n}$

The skewed fractional notation is $x / n$

The linear fractional notation is $x / n$

And the decimal notation of $\frac{x}{n}$ is $a$, and it is a real number

Also, $y$ units of $x P P n=\frac{y\left(\frac{x}{n}\right)}{y}$

let, $z=y\left(\frac{x}{n}\right)$,

Then, $y$ units of $x P P n=\frac{z}{y}$

And henceforth $[\mathrm{y}](\mathrm{xPPn})$ stands for "y units of xPPn"

Accordingly, $[\mathrm{y}](\mathrm{xPPn})=\frac{\mathrm{z}}{\mathrm{y}}-----(5)$

Here the numerator indicates active ingredient and the denominator indicates solution or drug. 
Table-2: $x$ Parts Per ' $10^{n}$,

\begin{tabular}{|c|c|c|c|c|c|}
\hline$\frac{x}{10^{n}}$ & $\begin{array}{l}\text { Verbal form of the } \\
\text { expression }\end{array}$ & Abbreviation & $\begin{array}{l}\text { Alphanumeric } \\
\text { notation }\end{array}$ & $\begin{array}{l}\text { Prevailing } \\
\text { notation }\end{array}$ & $\begin{array}{l}\text { Decimal } \\
\text { form }\end{array}$ \\
\hline$\frac{x}{10}$ & $\mathrm{x}$ Parts per ten & $\mathrm{x} \mathrm{PPt}$ & x PP10 & - & $0 . x$ \\
\hline$\frac{x}{10^{2}}$ & $\begin{array}{l}\text { x Parts per hundred } \\
\text { Or } \\
\text { Parts per cent } \\
\text { Or } \\
\text { PERCENT }\end{array}$ & $\begin{array}{l}\text { x PPh } \\
\text { or } \\
\text { PPc }\end{array}$ & $\mathrm{x} P \mathrm{PP} 10^{2}$ & $x \%$ & $0.0 x$ \\
\hline$\frac{x}{10^{3}}$ & $\begin{array}{l}\mathrm{x} \quad \text { Parts } \\
\text { Thousand }\end{array}$ & x PPth & x PP10 $10^{3}$ & $x \%_{0}$ & $0.00 x$ \\
\hline$\frac{x}{10^{4}}$ & $\begin{array}{l}\mathrm{x} \text { Parts per } \\
\text { thousand }\end{array}$ & x PPtth & $\mathrm{x}$ PP10 & - & $0.000 x$ \\
\hline$\frac{x}{10^{5}}$ & $\begin{array}{l}\text { x Parts per hundred } \\
\text { thousand }\end{array}$ & x PPhth & $\mathrm{x}$ PP10 5 & - & $0.0000 x$ \\
\hline$\frac{x}{10^{6}}$ & $\mathrm{x}$ Parts per million & x PPm & x PP10 $10^{6}$ & - & $0.00000 x$ \\
\hline
\end{tabular}

In addition to this, some more basic factors are intertwined in nature, with the $\mathrm{x}$ PPn. Those are volume, mass and weight. $x / n$ may be understood in terms of $: x / n(v / v)$ or $x / n(w / w)$ or $x / n(v / w)$ or $x / n(w / v)$.

If the volume does not change after mixing and if $\mathrm{ml}$ and $\mathrm{g}$ are the units of volume and mass ,

Then, $\frac{x}{n}\left(\frac{v}{v}\right)=\frac{x}{(y+x)}$, because $n=(y+x)$

Similarly, $x / n(w / w)=\frac{x g}{(y+x) g}, x / n(v / w)=\frac{x m l}{(y+w t . o f \times m l) g}$

Only in case of, $x / n(w / v)=\frac{x g}{n m l}$, here, volume of the active ingredient is not consideredbecause increase in volume of solution after dissolution of active ingredient will be negligible.

Example:. Peppermint spirit contains $10 \% \mathrm{v} / \mathrm{v}$ peppermint oil. What is the volume of the solvent when volume of spirit is $75 \mathrm{ml} ?[8]$

$: 10 \%(v / v)=\frac{10 \mathrm{ml}}{100 \mathrm{ml}}$

Factor that is required to make the numerator to 75 is $\frac{75}{10}$, multiplying both the numerator and denominator by this factor we

$$
\begin{aligned}
& : \frac{10 \mathrm{ml} \times \frac{75}{10}}{100 \mathrm{ml} \times \frac{75}{10}}=\frac{75 \mathrm{ml}}{750 \mathrm{ml}} \\
& :=\frac{75 \mathrm{ml}}{(675+75) \mathrm{ml}}
\end{aligned}
$$


This shows that volume of the solvent of $10 \%$ peppermint sprit is $675 \mathrm{ml}$.

\subsection{Summing of $x$ (PPn)}

\section{Case-1}

If $x_{1} P P n_{1}, x_{2} P P n_{1}, x_{3} P P n_{1} \cdots, x_{a} P P n_{1}$ are the solutions of different strengths and of same $P P n$.

( Here $a$ and $n$ are natural numbers)

: then,$\frac{x_{1}}{n_{1}}+\frac{x_{2}}{n_{1}}+\frac{x_{3}}{n_{1}}+\cdots+\frac{x_{a}}{n_{1}}=\frac{x_{1}+x_{2}+x_{3}+\cdots+x_{a}}{a n_{1}}-----(6)$

: to simplify(6)let, $x_{1}+x_{2}+x_{3}+\cdots+x_{a}=y$

$: \operatorname{Then}(6),=\frac{(y / a)}{n_{1}}------(7)$

: And if,$(y / a)=z$

: Then $(6)=\frac{z}{n_{1}}$

$:=z / n_{1}\left(\frac{w}{w} \operatorname{or} \frac{v}{v} \operatorname{or} \frac{w}{v}\right.$ or $\left.\frac{v}{w}\right)$

$:=z P P n_{1}\left(\frac{w}{w} \operatorname{or} \frac{v}{v} \operatorname{or} \frac{w}{v}\right.$ or $\left.\frac{v}{w}\right)$

If $n_{1}=100$, the result will be $=z \%$

Example: What is the percentage strength of the solution when equal quantities of 10\%, 20\%, 30\% solutions are mixed together.

Here, $x_{1}=10, x_{2}=20, x_{3}=30$, and $n_{1}$ can be $=100$, then using (6), we have

$$
\begin{aligned}
& : \frac{10}{100}+\frac{20}{100}+\frac{30}{100}=\frac{10+20+30}{300} \\
& =\frac{20}{100} \\
& =20 \%
\end{aligned}
$$

Case-2: To find the strength of the solution to a specified base when different strength, different quantity,

different PPn solutions are mixed together.

Let $[b] P P n_{1},[c] P P n_{2},[d] P P n_{3}, \cdots,[f] P P n_{a}$ be the solutions to be mixed,

and let $n_{y}$ be the specified base i.e., $P P n_{y}$ and let ${ }_{z P P} n_{y}$ be the final solution,

: then, sum of them is $=[b]\left(\frac{x_{1}}{n_{1}}\right)+[c]\left(\frac{x_{2}}{n_{2}}\right)+[d]\left(\frac{x_{3}}{n_{3}}\right)+\cdots+[f]\left(\frac{x_{a}}{n_{a}}\right)$

$$
\begin{aligned}
: & =\frac{b\left(\frac{x_{1}}{n_{1}}\right)}{b}+\frac{c\left(\frac{x_{2}}{n_{2}}\right)}{c}+\frac{d\left(\frac{x_{3}}{n_{3}}\right)}{d}+\cdots+\frac{f\left(\frac{x_{a}}{n_{a}}\right)}{f} \\
: & =\frac{\frac{b x_{1}}{n_{1}}+\frac{c x_{2}}{n_{2}}+\frac{d x_{3}}{n_{3}}+\cdots+\frac{f x_{a}}{n_{a}}}{(b+c+d+\cdots+f)}----(8)
\end{aligned}
$$

The required and specified base of strength is $n_{y}$, then (8) will be, 


$$
\begin{aligned}
& : \quad=\frac{\frac{n_{y}\left(\frac{b x_{1}}{n_{1}}+\frac{c x_{2}}{n_{2}}+\frac{d x_{3}}{n_{3}}+\cdots+\frac{f x_{a}}{n_{a}}\right)}{(b+c+d+\cdots+f)}}{n_{y}}----(9) \\
& \text { Let }, \frac{n_{y}\left(\frac{b x_{1}}{n_{1}}+\frac{c x_{2}}{n_{2}}+\frac{d x_{3}}{n_{3}}+\cdots+\frac{f x_{a}}{n_{a}}\right)}{(b+c+d+\cdots+f)}=z \text {, then (9)will be } \\
& :=\frac{z}{n_{y}} \quad \text { (9) can be written as, } z P P n_{y}, \text { if } n_{y}=100, \text { the result will be } z \%
\end{aligned}
$$

Exmple-1: What is the percentage strength $(\mathrm{v} / \mathrm{v})$ of alcohol in a mixture of $3000 \mathrm{ml}$ of $40 \% \mathrm{v} / \mathrm{v}$ alcohol, $1000 \quad \mathrm{ml}$ of 60 $\% \mathrm{v} / \mathrm{v}$ alcohol, and $1000 \mathrm{ml}$ of $70 \% \mathrm{v} / \mathrm{v}$ alcohol? Assume no contraction of volume after mixing.[9]

: Here $n_{y}=100$ and $x_{1}=40, x_{2}=60, x_{3}=70$, Also, $b=3000, c=1000, d=1000$

and $n_{1}=n_{2}=n_{3}=100$,

putting these values in(9) we get

$:$ Percentage strength $=\frac{\frac{3000 \times 40+1000 \times 60+1000 \times 70}{(3000+1000+1000)}}{100}$

Note: since $n_{1}=n_{2}=n_{3}=100$, and $n_{y}=100$, they get cancelled by one another.

$$
\begin{aligned}
& :=\frac{50}{100} \\
& :=50 \%
\end{aligned}
$$

Example-2: When the same problem is solved for $n_{y}=1000$, i.e., for $\frac{x}{1000}$ or PPth

$$
\begin{array}{ll}
: \text { xPth } & =\frac{\frac{1000\left(\frac{3000 \times 40+1000 \times 60+1000 \times 70}{100}\right)}{(3000+1000+1000)}}{1000} \\
: \quad=\frac{500}{1000}
\end{array}
$$

Example-3: Same problem, when $n_{1}=1000, n_{2}=2000, n_{3}=5000$ and $n_{y}=100$

$$
\begin{aligned}
: x P P C & =\frac{\frac{100\left(\frac{3000 \times 40 \times 10+1000 \times 60 \times 5+1000 \times 70 \times 2}{10000}\right)}{5000}}{100} \\
: \quad=3.28 \% &
\end{aligned}
$$

This problem can also be solved by another method as following

$$
\begin{aligned}
& : 3000 \mathrm{ml} \text { of } \frac{40}{1000} \text { strength solution }=\frac{3000\left(\frac{40}{1000}\right)}{3000}=\frac{120}{3000} \\
& : 1000 \mathrm{ml} \text { of } \frac{60}{2000} \text { strength solution }=\frac{1000\left(\frac{60}{2000}\right)}{1000}=\frac{30}{1000} \\
& : 1000 \mathrm{ml} \text { of } \frac{70}{5000} \text { strength solution }=\frac{1000\left(\frac{70}{5000}\right)}{1000}=\frac{14}{1000}
\end{aligned}
$$

Sum of these solutions are

$$
\begin{aligned}
& \frac{120}{3000}+\frac{30}{1000}+\frac{14}{1000} \\
& :=\frac{164}{5000} \\
& :=\frac{164}{50 \times 100} \\
& :=3.28 \%
\end{aligned}
$$


Example-4: A pharmacist adds $10 \mathrm{ml}$ of a $20 \%(\mathrm{w} / \mathrm{v})$ solution of a drug to $500 \mathrm{ml}$ of $\mathrm{D} 5 \mathrm{~W}$ for parenteral What is the percentage strength of the drug in the infusion solution? [10]

infusion.

Data: $x_{1}=20, x_{2}=0$, since the active ingredient dextrose in $D_{5} W$ is not considered in this case,

$b=10, c=500$ and $n_{y}=100, n_{1}=n_{2}=100$

$x P P h=\frac{\frac{100\left(\frac{10 \times 20}{100}+\frac{500 \times 0}{100}\right)}{10+500}}{100}$

$=\frac{0.392}{100}$

$=0.392 \%$

This is also solvable in another way as following:

$10 \mathrm{ml}$ of $20 \%$ solution is added to $500 \mathrm{ml}$ of D5W.Here D5W is a dummy drug with respect to this problem this statement can be written mathematically as following.

$: \quad x P P h(w / v)=\frac{0}{500 m l(D 5 W)}+\frac{20 \%}{10 m l}$

To convert $20 \%$ into the quantity of active ingredient it is multiplied by 10 which is the quantity added.

$$
\begin{aligned}
& :=\frac{0}{500 m l(D 5 W)}+\frac{\frac{20}{100} \times 10}{10 m l} \\
& =\frac{0}{500 m l(D 5 W)}+\frac{2 g}{10 m l}
\end{aligned}
$$

By direct addition, we get.

$$
\begin{aligned}
& =\frac{2 g}{510 m l(D 5 W)} \\
& =\frac{2 g}{5.10 \times 100 m l(D 5 W)} \\
& =\frac{0.39 g}{100 m l(D 5 W)} \\
& =0.39 \%(w / v)
\end{aligned}
$$

Example-5:Prepare $250 \mathrm{ml}$ of dextrose $7.5 \% \mathrm{w} / \mathrm{v}$ using dextrose $5 \%\left(D_{5} \mathrm{~W}\right) \mathrm{w} / \mathrm{v}$ and dextrose $50 \%\left(D_{50} \mathrm{~W}\right)$ How many milliliters of each will be needed?[11]

Method-1: using (9)

Data: $x=7.5, n=100, x_{1}=5, x_{2}=50, n_{1}=100, n_{2}=100 . n_{y}=100$.

$$
\begin{aligned}
& : \frac{7.5}{100}=\frac{\frac{100\left[\left(\frac{5 b}{100}\right)+\left(\frac{50 c}{100}\right)\right]}{b+c}}{100} \\
& : \frac{7.5}{100}=\frac{5 b+50 c}{100(b+c)}
\end{aligned}
$$


IOSR Journal of Pharmacy

Vol. 2, Issue 1, Jan-Feb.2012, pp. 113-129

$: 500 b+5000 c=750 b+750 c$

$: 250 b=4250 c$

$: \frac{b}{c}=\frac{17}{1}$

$: b=17$ and $c=1$

Check: Putting values of $b$ and $c$ in (9) we get.

$:=\frac{\frac{100\left[\left(\frac{5 \times 17}{100}\right)+\left(\frac{50 \times 1}{100}\right)\right]}{17+1}}{100}$

$;=\frac{7.5}{100}$

$:=7.5 \%$

Now, to prepare $250 \mathrm{ml}, \frac{250}{(1+17)}=13.89 \mathrm{ml}$ of $50 \%$ Dextose and $250-13.89=236.11 \mathrm{ml}$ of $5 \%$ Dextrose are required

Example-6: In what proportion should alcohols of 95\% and 50\% strengths be mixed to make 70\% alcohol? [12]

Method-1:This can be solve by using (9) as usual.

Method-2: Here determinant is used to solve the problem.

Let $x$ and $y$ be the factors that modify the given ratios of percentage to $\frac{70}{100}$,

this can be written as,$\frac{95 x}{100 x}+\frac{50 y}{100 y}=\frac{70}{100}$

Then, $95 x+50 y=70------(10)$

And, $100 x+100 y=100$

i.e., $x+y=1$

Using (10)\&(11)the detrminant $\Delta$ can be written as following,

$: \Delta=\left|\begin{array}{cc}95 & 50 \\ 1 & 1\end{array}\right|$

$:=45$

Let $\Delta_{x} \& \Delta_{y}$ be the remaining determinants formed w.r.t RHS,

: Then, $\Delta_{x}=\left|\begin{array}{cc}70 & 50 \\ 1 & 1\end{array}\right|$

$: \quad=20$

$:$ And, $\Delta_{y}=\left|\begin{array}{cc}95 & 70 \\ 1 & 1\end{array}\right|$

$: \quad=25$ 
: Now, $x=\frac{\Delta_{x}}{\Delta}$ and $y=\frac{\Delta_{y}}{\Delta}$

: i.e., $x=\frac{20}{45}$ and $y=\frac{25}{45}$

: $\quad x=\frac{4}{9}$ and $y=\frac{5}{9}$

$\quad \frac{x}{y}=\frac{4}{5}$

: $\quad$ Then, $x=4$ and $y=5$

Example-7: A hospital pharmacist wants to use lots of zinc oxide ointment containing, respectively, $50 \%$, $20 \%$, and $5 \%$ of zinc oxide. In what proportion should they be mixed to prepare a $10 \%$ zinc oxide ointment?[13]

\section{Method-1:}

Data: $n_{y}=100, x_{1}=50, x_{2}=20, x_{3}=5, n_{1}=n_{2}=n_{3}=100$, and required strength is $10 \%$

Using

$: \frac{10}{100}=\frac{\frac{100\left(\frac{50 b}{100}+\frac{20 c}{100}+\frac{5 d}{100}\right)}{(b+c+d)}}{100}$

$\frac{10}{100}=\frac{50 b+20 c+5 d}{100 b+100 c+100 d}$

$: 1000 b+1000 c+1000 d=5000 b+2000 c+500 d$

$: 1 d=8 b+2 c$

: When, $d=1$, above equation will be, $8 b+2 c=1$

: Now, by trial and error method we can find $b=\frac{1}{16}$ and $c=\frac{1}{4}$

Then, the proportion of $b: c: d=\frac{1}{16}: \frac{1}{4}: 1$

By multiplying RHS of the above equation by 16 , we have,

$$
=1: 4: 16
$$

Assigning different values to $d$ we can get different proportions. For example when $d=10$, consequently $b=1$ and $c=1$ which is the result obtained in [14]. Also, we can get the result by giving convenient values to $\mathrm{b}$ and $\mathrm{c}$ such that satisfies the equation.

\section{Method-2:}

Given, $50 \%, 20 \%$, and 5\% zinc oxide ointment and the required percentage is $10 \%$. Keeping $50 \%$ and 20 $\%$ ointments as fixed. And considering $5 \%$ ointment as the variable.

Then, let the variable base (solvent) $t=100$

Then, $5=0.05 t$ 
: i.e, $50 \%+20 \%+0.05 t \%=10 \%$

$: \frac{50}{100}+\frac{20}{100}+\frac{0.05 t}{t}=\frac{10}{100}----(12)$

$: \frac{70+0.05 t}{200+t}=\frac{10}{100}$

$: 100(70+0.05 t)=10(200+t)$

$: 7000+5 t=2000+10 t$

$: t=1000$

: Consequently (12) is , $\frac{50}{100}+\frac{20}{100}+\frac{50}{1000}=\frac{10}{100}$

: Proportion of denominator of LHS is 100: 100: 1000

: which is equal to 1:1:10

Without using (9) answer can be found directly as following

Let all the three percentages be variables. And let $t_{1}, t_{2}, t_{3}$ be the variable quantities

$$
\begin{aligned}
& : \text { Then }, \frac{0.5 t_{1}}{t_{1}}+\frac{0.2 t_{2}}{t_{2}}+\frac{0.05 t_{3}}{t_{3}}=\frac{10}{100} \\
& : 50 t_{1}+20 t_{2}+5 t_{3}=10 t_{1}+10 t_{2}+10 t_{3} \\
& : 8 t_{1}+2 t_{2}=t_{3}
\end{aligned}
$$

As usual answers can be found by giving different values to $t_{3}$ or to $t_{1} \& t_{2}$

Note: Since problem has three unknown and only two rows, square matrix cannot be formed. Hence it is not to draw solution by determinant method. Although, by modifying some of the rules of determinants answer can be obtained.

possible matrix,

Example-8: If $50 \mathrm{ml}$ of a 1:20 $\mathrm{w} / \mathrm{v}$ solution are diluted to $1000 \mathrm{ml}$, what is the ratio strength ( $\mathrm{w} / \mathrm{v}) ?[14]$

Method-1: Using (9).

Here two ratio strength solutions are found that are 1) 1:20 solution and 2) the diluent which can be written as Here base of the diluent is arbitrary hence convenient base is chosen in this case. Also, $n_{y}$ is also a random number 0:20. can be chosen according to our convenience.

$$
\begin{aligned}
& \text { Data: } x_{1}=1, x_{2}=0, b=50, c=950, n_{y}=1000 \\
& : \text { Ratio strength }=\frac{\frac{1000\left(\frac{50 \times 1}{20}+\frac{950 \times 0}{20}\right)}{50+950}}{1000} \\
& : \quad=\frac{2.5}{1000} \\
& : \quad=\frac{1}{400}
\end{aligned}
$$


In this way problems on percentage and PPn of different parameters can be solved by using (9).

\section{Conversion of percentage to $\mathbf{m g} / \mathbf{m l}$ and vice versa:}

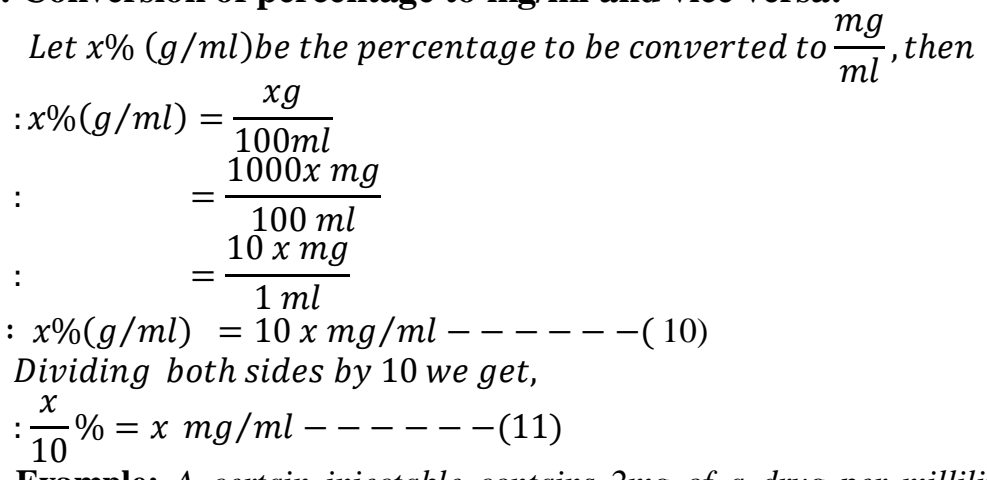

Example: A certain injectable contains $2 m g$ of a drug per milliliter of solution. What is the ratio Strength (w/v) of the solution?[15]

Using (11), we have.

$: 2 \mathrm{mg} / \mathrm{ml}=\frac{2}{10} \%$

$:=0.2 \%=\frac{2}{1000}=1: 500$

\section{MEANING OF 0\% AND 0 PPn}

$0=0 P P n$

Proof:-

Given, 0

multiply it by $n P P n$

$:=0\left(\frac{n}{n}\right)$

$:=\frac{0 \times n}{n}$

$:=\frac{0}{n}$

$:=0 P P n$

: Decimal notation of this is $=0$

Thus proved

0 PPn or $0 / n$ or $\frac{0}{n}$ is used to denote pure base, solvent or vehicle.

Example-1:

$$
: 0=0 \times\left(\frac{100}{100}\right)
$$




$$
\begin{array}{ll}
: & =\frac{0}{100} \\
: & =0 \%
\end{array}
$$

Decimal notation of $0 \%$ [ils 0

Example-2: If $50 \mathrm{ml}$ of a 1:20 w/v solution are diluted to $1000 \mathrm{ml}$, what is the ratio strength $(\mathrm{w} / \mathrm{v})$ ?

$50 \mathrm{ml}$ of 1: 20 strength solution is diluted to $1000 \mathrm{ml}$. This statement can mathematically be written as,

$$
\text { : } \frac{50\left(\frac{1}{20}\right)}{50}+\frac{0}{950}
$$

Adding numerator and denominator directly (6), we have

$$
\begin{aligned}
& :=\frac{2.5}{1000} \\
& :=\frac{1}{400}
\end{aligned}
$$

\subsection{MEANING OF $X / 0$ OR $\frac{X}{0}$}

This kind of notation may leads to confusion. Addition of ingredient is in one way simple and in another complex because of factors like solubility and saturation point of a solution. Hence this kind of notation is not necessary in pharmacy.

This kind of notation can be used to indicate that the drug is not in the form of solution or in any form of And it may also imply that the solvent is completely removed.

mixture.

8.2. Removal of solvent by any means. (Usually by evaporation)

Example: If a syrup containing $65 \% \mathrm{w} / \mathrm{v}$ of sucrose is evaporated to $85 \%$ of its volume, what percentage $(w / v)$ of sucrose will it contain?[16]

\section{Method -1:}

$: 65 \% \mathrm{w} / \mathrm{v}=\frac{65 \mathrm{~g}}{100 \mathrm{~m}}$

This syrup is evaporated to $85 \%$ of its volume means, $15 \%$ of solvent is evaporated or $15 \mathrm{ml}$ of it is evaporated if volume of solution is $100 \mathrm{ml}$.

$: i . e ., \frac{65 \mathrm{~g}}{100 \mathrm{~m}}-\frac{0}{15 \mathrm{ml}}$

By direct subtraction of numerator and denominator we have the above expression equal to

$$
:=\frac{65 \mathrm{~g}}{85 \mathrm{~m}}
$$

: Furt her, to find the persentage

$$
\frac{65 \mathrm{~g} \times \frac{100}{85}}{85 \mathrm{~m} \times \frac{100}{85}}=\frac{76.47 \mathrm{~g}}{100 \mathrm{~m}}=76.47 \%
$$




\section{Method -2:}

$$
\begin{aligned}
& : \frac{65}{100 \times 85 \%} \\
& : \frac{65}{85}
\end{aligned}
$$

To find the percentage strength

$$
\begin{aligned}
& : \frac{65 \times \frac{100}{85}}{85 \times \frac{100}{85}} \\
& : \quad \frac{76.47}{100} \\
& :=76.47 \%
\end{aligned}
$$

\section{Solution to Miscellaneous problems.}

Problem No.-1:In acute hypersensitivity reactions, $0.5 \mathrm{~mL}$ of a 1:1000 (w/v) solution of epinephrine may be administered subcutaneously or intramuscularly, calculate the milligrams of epinephrine given.[17]

Solution:

$$
: \frac{1}{1000}(w / v)=\frac{1 g}{1000 \mathrm{ml}}=\frac{1000 \mathrm{mg}}{1000 \mathrm{ml}}=\frac{0.5 \mathrm{mg}}{0.5 \mathrm{~m}}
$$

Hence $0.5 \mathrm{mg}$ of epinephrine is given

ProblemNo.2: How many grams of $10 \% \mathrm{w} / \mathrm{w}$ ammonia solution can be made from $1800 \mathrm{~g}$ of $28 \%$ strong ammonia solution?[17]

Solution: Let $a$ be the required

$$
\text { volume of } 10 \% \text { ammonia solution , then }
$$

: $a\left(\frac{10}{100}\right)=1800\left(\frac{28}{100}\right)$

$: \quad a=5040$

Problem.No.3: How many grams of a substance should be added to $240 \mathrm{ml}$ of water to make a $4 \%$ (w/w) solution?[18]

Solution:

$: 4 \%(w / w)=\frac{4}{96+4}$

To make 96 equal to 240 multiply all the elements of RHS by the factor $\frac{240}{96}$.

$:=\frac{4\left(\frac{240}{96}\right)}{96\left(\frac{240}{96}\right)+4\left(\frac{240}{96}\right)}$ 


$$
:=\frac{10 g}{240 g+10 g}
$$

\section{Conclusion:}

Aim of this article is to give more scientific and algebraic touch to the pharmaceutical calculations. Also, an effort is made to make the steps of the solutions more pragmatic and easily understandable. And, an attempt is made to draw solutions from basic datum or from data. A good relation is maintained between every steps of the solutions.

\section{References \\ Books:}

[1] Howard C. Ansel, Pharmaceutical Calculations (Wolters Kluwer Health | Lippincott Williams \& Wilkins 530 Walnut Street,Philadelphia Pa 19106, 2010)

[2] Don A. Ballington, Tova Wiegand Green, Pharmacy Calculations (EMC Corporation, USA, 2007)

\section{PageNo. and Section No.}

[3] Howard C. Ansel,, Pharmaceutical Calculations (Wolters Kluwer Health | Lippincott Williams \& Wilkins 530 Walnut Street,Philadelphia Pa 19106, 2010),p.3

[4] Don A. Ballington, Tova Wiegand Green, Pharmacy Calculations (EMC Corporation, USA, 2007),sec.2.2.3

[5] Howard C. Ansel,, Pharmaceutical Calculations (Wolters Kluwer Health | Lippincott Williams \& Wilkins 530 Walnut Street,Philadelphia Pa 19106, 2010),p.9

[6] Howard C. Ansel, Pharmaceutical Calculations (Wolters Kluwer Health | Lippincott Williams \& Wilkins 530 Walnut Street,Philadelphia Pa 19106, 2010),p.22

[7] Howard C. Ansel, Pharmaceutical Calculations (Wolters Kluwer Health | Lippincott Williams \& Wilkins 530 Walnut Street,Philadelphia Pa 19106, 2010),p.30, Pr. No. 1

[8] Howard C. Ansel, Pharmaceutical Calculations (Wolters Kluwer Health | Lippincott Williams \& Wilkins 530 Walnut Street,Philadelphia Pa 19106, 2010),p.85

[9] Howard C. Ansel, Pharmaceutical Calculations (Wolters Kluwer Health | Lippincott Williams \& Wilkins 530 Walnut Street,Philadelphia Pa 19106, 2010),p.264

[10] Howard C. Ansel, Pharmaceutical Calculations (WoltersKluwer Health | Lippincott Williams \& Wilkins 530 Walnut Street,Philadelphia Pa 19106, 2010),p.95, pr.No.20

[11] Don A. Ballington, Tova Wiegand Green, Pharmacy Calculations (EMC Corporation, USA, 2007),sec.8.3.1

[12] Howard C. Ansel, Pharmaceutical Calculations (WoltersKluwer Health | Lippincott Williams \& Wilkins 530 Walnut Street,Philadelphia Pa 19106, 2010),p.265

[13] Howard C. Ansel, Pharmaceutical Calculations (WoltersKluwer Health | Lippincott Williams \& Wilkins 530 Walnut Street,Philadelphia Pa 19106, 2010),p.266

[14] Howard C. Ansel, Pharmaceutical Calculations (WoltersKluwer Health | Lippincott Williams \& Wilkins 530 Walnut Street,Philadelphia Pa 19106, 2010),p.253

[15] Howard C. Ansel, Pharmaceutical Calculations (WoltersKluwer Health | Lippincott Williams \& Wilkins 530 Walnut Street,Philadelphia Pa 19106, 2010),p. 90

[16] Howard C. Ansel, Pharmaceutical Calculations (WoltersKluwer Health | Lippincott Williams \& Wilkins 530 Walnut Street,Philadelphia Pa 19106, 2010),p.253

[17] Howard C. Ansel, Pharmaceutical Calculations (WoltersKluwer Health | Lippincott Williams \& Wilkins 530 Walnut Street,Philadelphia Pa 19106, 2010),98. pr.No.65

[18] Howard C. Ansel, Pharmaceutical Calculations (WoltersKluwer Health | Lippincott Williams \& Wilkins 530 Walnut Street,Philadelphia Pa 19106, 2010),p.86 